\title{
THE VOCAL SCORE PROFILE IN VERDI'S CHARACTERS
}

Pizzorni N*, SLP, Schindler A**, PROF, Sozzi M*, PhD, Corbo M*, MD Gilardone M*, MD

*Department of Neurorehabilitation Sciences, Casa di Cura del Policlinico, Milan, Italy

**Department of Biomedical and Clinical Sciences "L. Sacco", University of Milan, Milan, Italy

\section{Corresponding author:}

Nicole Pizzorni

Servizio di Foniatria e Logopedia, Casa di Cura del Policlinico

Via Giuseppe Dezza 48, 20144 Milano, Italy

nicole.pizzorni@virgilio.it

tel. +390248593412

Conflict of interest: all the authors declare that they have no conflict of interest.

Running title: The VSP in Verdi's characters 


\begin{abstract}
Objective: Selecting the appropriate repertoire for an opera singer may be crucial for both the prevention of voice disorders and the career progression. Here, we reviewed the score of 14 Verdi's operas to gain the data for the creation of the vocal score profile of each role.
\end{abstract}

Methods: Seven musicians were involved in the analysis process. Notes were counted and reported as absolute and relative frequency. Pitch measurements included pitch range, percentage of high-pitched notes, percentage of medium-pitched notes, percentage of low-pitched notes, high-pitched and low-pitched notes rate, percentage of the notes in the passaggio, identification of the prevalent octave, percentage of notes in the prevalent octave, percentage of notes in a moderate range tessitura. The total phonation time was calculated for each character.

Results: A heterogeneity among pitch and duration measurement was found among roles within the same voice type, leading to highly different vocal efforts required by the performer.

Conclusions: Data on 67 Verdi characters were gained and the vocal demand of each role was discussed. Potentially, these results may support singers, singing teachers and vocal coaches in the selection of the repertoire. The data may also assist clinicians in the conduction of counseling and during eventual voice therapy. Future studies must investigate the predictive value of the VSP in appraising the risk of vocal injury.

Key words: Vocal score profile, Verdi, Opera, Singing, Laryngology 


\section{Introduction}

Voice disorders have been reported with a prevalence ranging from $28.65 \%$ to $53 \%$ in classical singers [1], and, phonotraumatic lesions are the most common etiology [2]. Selecting the appropriate repertoire for an opera singer may be crucial for both the success of the performance, the career progression, and the prevention of voice disorders. The story of some eminent opera singers are examples of vocal and/or careers' decline due to inadequate repertoire selection [3-4]. Beside consideration on age, gender, personality, preferences, technical and expressive skills, during last decades several tools have been developed in the field of laryngology to assist singers, singing teachers and vocal coaches in this choice.

First of all, the vocal range profile (VRP) or phonetogram, a 2-dimensional display of the range of a voice in frequency and in amplitude firstly proposed in 1953 by Calvet [5]. It provides an objective measure of the opera singer voices as a complementary tool to the singing teacher's hearing [6-7]. On the other hand, although voice could be adequately classified, singers may be exposed to the risk of phonotrauma since the role assigned may not suit the performer's vocal characteristics. Therefore, in 1988 Stefan Thurmer introduced the concept of "tessiturogram" [8].

The tessiturogram is a histogram portraying the frequency of note occurrence within each composition or piece. In other words, it is the equivalent of VRP by the scoring perspective and may be suggestive of the vocal demand of a specific role. Afterward, Titze developed Thurmer's tessiturogram by adding measurements of the duration and the frequency in Hertz of each sung pitch [9]. Further improvements were proposed by Fussi and colleagues who associated several indexes of vocal demands to the tessiturogram, that they renamed "vocal score profile" (VSP) [10]. Moreover, the same authors proposed to assess vocal economy of a role comparing the VRP of the opera singer with the VSP of the score. Nix analyzed a Mozart composition through Titze's tessiturogram and combined the data with the VRP of a singer and the dosimetry derived from the performance of the same song [11]. The author highlighted several limits of the tessiturogram, such as the inaccuracy in estimating the short-term recovery and the inability to address the kind of singing. However, he found a sufficient correspondence between the estimated and the actual values for voicing time dose and cycle dose and concluded that the combination of the three tools may represent a helpful battery to guide repertoire selection. Nevertheless, performing the tessiturogram is highly time-consuming and therefore represent a 
barrier to its systematic use in daily practice since, nowadays, no automatic extraction process from digital files of musical scores is still available [12].

Among the opera composers, Giuseppe Verdi's operas have been the most performed over the five seasons 2011/12 to 2015/16, with 3728 productions and 16265 performances all over the world [13]. Despite the size of these numbers, no data are yet available to allow singers, teachers, and laryngologists to create VSP of Verdi's roles. Therefore, our study aimed to analyze the scores of 67 characters from 14 Verdi's operas to extract objective information for the creation of the VSP of these roles. Knowledge of the magnitude of vocal demand, concerning pitch and duration, required by most performed Verdi's roles is the focus of the study. Singers, singing teachers and vocal coaches may benefit from the availability of these data in the selection of the repertoire. Moreover, these results may potentially be of clinical utility for phoniatricians, otorhinolaryngologists and speech and language therapists (SLTs) when conducting periodic evaluations of the singers' voice for the prevention the onset of laryngeal abnormalities, and, when a voice disorder already occurs, for appraising the role of the repertoire on its development as well as for the conduction of voice therapy. 


\section{Materials and methods}

The scores of 14 Verdi's opera were analyzed: 3 operas of the early period (until 1849: Nabucodonosor, Ernani, Macbeth), 4 operas of the middle period (1850-1857: Rigoletto, Il Trovatore, La Traviata, Les Vêpres Siciliennes, Simon Boccanegra), 5 operas of the late period (1859-1871: Un Ballo in Maschera, La Forza del Destino, Don Carlos, Aida), 2 final works (from 1874: Otello, Falstaff), according to Julian Budden's classification [14]. Overall, 67 roles were examined: 16 soprano roles, 8 mezzo-soprano and contralto roles, 15 tenor roles, 17 baritone roles, 11 bass roles. Seven musicians, pianists or singers, and conservatory graduates were involved in the analysis process after a training session on measurement procedure. Pitch and duration indexes were measured for each character's scores, based on the VSP as proposed by Gilardone \& Fussi in 1998 [13].

For notes' counting, each note was considered as a unit regardless of its duration. Concerning the grace notes, the acciaccatura and the appoggiatura were considered as a unit, while notes in the trills were not considered. For each character, the frequency of every note in the score was, therefore, computed. Notes were designated according to the international pitch notation system was [15].

Pitch measurements included pitch range, percentage of high-pitched notes, percentage of medium-pitched notes, percentage of low-pitched notes, high-pitched and low-pitched notes rate, percentage of the notes in the passaggio, identification of the prevalent octave, percentage of notes in the prevalent octave, percentage of notes in a moderate range tessitura.

The pitch range (PR) represent the vocal range extension required for a certain character and correspond to the distance between the highest-pitched note and the lowest-pitched notes of the score.

The percentage of high-pitched (\%Hp), medium-pitched (\%Mp) and low-pitched notes (\%Lp) was calculated considering high-pitch notes those included between the secondo passaggio (included) and the highest-pitched note, medium-pitched notes those included between the primo and the secondo passaggio (excluded) and lowpitched notes those included between the lowest-pitched note and the primo passaggio (included). The specific note of the secondo and primo passaggio varies among singers within the same voice type. However, to allow a generalization of the results a certain degree of approximation is required. Five different essays defining 
register's limits were consulted [13;16-19]. Different register's limits were reported among the 5 essays; hence, average notes were derived for each voice type (Table 1 ). The three indexes $\% \mathrm{Hp}, \% \mathrm{Mp}$, and $\% \mathrm{Lp}$ provide information on the vocal effort required by the score, as it is increased when the performer sing in the upper or lower register. Indeed, while medium-pitched notes are the results of a steady contraction of intrinsic laryngeal muscles, the contraction of the thyroarytenoid muscle is prevalent in the production of low-pitched, while a higher activity of the cricothyroid muscle is observed in the high-pitched notes. Moreover, the highpitched and low-pitched notes rate $(\mathrm{Hp} / \mathrm{Lp})$ was calculated to highlight a potential imbalance between vocal registers. The closer the $\mathrm{Hp} / \mathrm{Lp}$ to 0 , the more prevalent the notes of the lower register; the greater than 1 , the more prevalent the notes of the upper register.

The percentage of notes in the passaggio $(\% \mathrm{P})$ was calculated. Passaggio notes require delicate changes of laryngeal and resonant behavior: in the secondo passaggio, the performer must balance the need of lengthening the vocal folds with the action of the thyroarytenoid muscle to keep a complete glottal contact and the vibration of the whole vocal fold. Therefore $\% \mathrm{P}$ is another index of vocal effort.

The octave (eight consecutive notes) containing the higher number of notes was identified as the prevalent octave $(\mathrm{PO})$, and the percentage of notes belonging to the $\mathrm{PO}(\% \mathrm{PO})$ was measured. Furthermore, the percentage of notes at a moderate range tessitura $(\% \mathrm{Mt})$ was recorded counting the number of notes belonging to the PO and subtracting those of the upper and the lower register. Interesting considerations can raise from the comparison between the $\% \mathrm{Mt}$ with the $\% \mathrm{PO}$ to measure the vocal comfort of a role.

For the duration analysis, using the metronome marking for the quarter note specified by the composer, the time duration of each rhythmic value indicated in the score was converted into seconds, and the results were afterward summed up. Whether the metronome markings were not indicated, the average time duration of the quarter note for each tempo or mood indication was used as reported in Table 2. The total phonation time (TPT) was calculated for each character.

\section{Data analysis}

The number of notes for each character is reported as absolute and relative frequency. Results of notes' counting have also been organized in histograms, reporting notes' pitch on the horizontal axis and absolute or 
relative frequency on the vertical axis, as a way to represent and compare pitch distribution of different roles. Characters have been divided into five voice type (bass, baritone, tenor, mezzo-soprano and contralto, soprano) and pitch and duration results have been organized in a single table for each voice type to allow an immediate comparison between the different roles. 


\section{Results}

Pitch and duration measurements for each character are reported in Table 3 to 7 on the basis of the voice type. Roles are organized in chronological order.

The pitch range varied from $\mathrm{C} \# 6$ to $\mathrm{F} \# 3$ for sopranos, from $\mathrm{C} 6$ to $\mathrm{G} 3$ for mezzo-sopranos and contraltos, from D5 to $\mathrm{Bb} 2$ for tenors, from $\mathrm{B} 4$ to $\mathrm{F} 2$ for baritones and from $\mathrm{F} \# 4$ to $\mathrm{E} 2$ for bass roles. High variability was found for the $\% \mathrm{Hp}$ and $\% \mathrm{Lp}$ within each voice category. Concerning sopranos, the $\% \mathrm{Hp}$ ranges from $9 \%$ of Alice and Nanetta to the $26 \%$ of Elvira, the \%Lp ranges from 13\% of Oscar to $33 \%$ of Desdemona; Hp notes are prevalent over Lp notes in 4/16 soprano roles. The $\% \mathrm{Hp}$ reaches its higher level within the category of mezzo-soprano and contralto with the $20 \%$ of Preziosilla, while represents only a $1 \%$ of the notes in Maddalena. The roles of Fenena, Azucena, and Preziosilla show a balance between Hp and Lp, while the latter is prevalent for the other roles of the category, with the peak of $47 \%$ of Lp notes and an $\mathrm{Hp} / \mathrm{Lp}$ of 0.07 for Quickly. Regarding male voices, $\% \mathrm{Hp}$ varies from $15 \%$ to $35 \%$ for tenors, from $2 \%$ to $11 \%$ for baritones and from $5 \%$ to $14 \%$ for basses, whereas $\%$ Lp varies from $8 \%$ to $18 \%$, from $9 \%$ to $35 \%$ and from $16 \%$ to $32 \%$ respectively. Two tenor roles have a Hp/Lp value lower than 1, while it was higher than 2 for $5 / 15$ roles. The $\mathrm{Hp} / \mathrm{Lp}$ ratio was lower than 1 for all but $1 / 17$ baritone and 1/11 bass roles.

The $\% \mathrm{P}$ was higher for tenors and mezzo-sopranos/contraltos than for other voice categories. Indeed, a \% $\mathrm{P}$ higher than $10 \%$ was found for $13 / 15$ tenor roles, for $6 / 8$ mezzo-soprano and contralto roles, for $6 / 16$ soprano roles, for $3 / 11$ bass roles and none of the baritone roles. Highest $\% \mathrm{PO}$ values were found for baritones, whereas lowest values were detected for sopranos. The $\% \mathrm{Mt}$ was higher than $80 \%$ for most of the baritone and bass roles, while lower than $80 \%$ for most of the soprano, mezzo-soprano/contralto and tenor roles. On average, soprano roles have the longest duration with a mean TPT of 23'8', (range 12'34' - 38'51'), followed by tenors (mean 20'18', range 6'41''-38'34'), baritones (mean 19'48', range 7'56''-29'13''), mezzo-sopranos and contraltos (mean 13'46', range 6'43''-21'24') and bass roles (mean 12'11'”, range 3'40''-28'41'').

Tables reporting the absolute and relative frequency of every note for each character are available as supplementary material. 
Figure 1 and Figure 2 show examples on how the present data can be used in order to compare different characters' scores and to better understand the vocal effort required by those roles; three tenor roles are compared (Cassio, Otello, and Fenton). Using relative frequency enables to compare the pitch distribution of the role apart from its duration, while the overall vocal demand is immediately visualized using absolute frequency. 


\section{Discussion}

The paper represents the first and preliminary report of the application of an objective method to gain numerical data for the generation of the VSP of Verdi's roles. Scores of 67 Verdi characters from 14 different operas were analyzed, and information on vocal demand for each role can be deduced from the results. Potentially, appraising vocal demand may be possible combining information on overall duration and technical difficulty of the role. Data of single pitch measurement should be interpreted together with all the other pitch variable. For instance, the value of \%Hp should be weighted based on the higher limit of the pitch range, while the value of $\% \mathrm{PO}$ should be compared to the value of $\% \mathrm{Mt}$ in order to highlight the degree of their overlap. Moreover, the predominance of the action of the thyroarytenoid muscle or of the cricothyroid muscle is represented by the $\mathrm{Hp} / \mathrm{Lp}$ ratio, but the effort required to each muscle varies depending on the \%Mp notes.

Verdi's vocality evolved over the years, moving from the Italian tradition of the beginning of the $19^{\text {th }}$ century to an innovative "conversational" singing. Within this evolution, sopranos gained a more deep vocality. Indeed, the low register became progressively predominant over the high register in these roles, and the $\% \mathrm{P}$ decreased. High phonation frequencies are associated with greater sub-glottal pressure [20] and greater vocal stiffness [21]. In the female first passaggio changes in vocal fold oscillation patterns are observed [22], while in the second passaggio both laryngeal, and resonance adjustments are required [23]; therefore, both passaggio regions are challenging to maintain steady vocal fold vibrations [24]. Hence, when ranking Verdi's soprano roles based on the vocal cost required, the effort required by the operas of the early period is higher than those of the late period. Above all, the roles of Elena and Violetta are the most demanding because of their duration, with nearly 5,000 notes and over 38 minutes of TPT. Among the two characters, a greater vocal effort is required for Elena due to the higher \%Lp and lower \%Mt. Consecutively the roles of Elvira and Lady Macbeth can be placed with high values of TPT, $\% \mathrm{Hp}$ and $\% \mathrm{P}$ and a low $\% \mathrm{Mt}$ for the former, while a high $\% \mathrm{Lp}$ and a low $\% \mathrm{Mp}$ beside a substantial TPT for the latter. A third group is represented by the roles of Abigaille and Gilda typified by their limited duration but low \%Mt and high \%Hp and \%P. The characters of Elisabetta, Amelia, Aida, and Oscar can be grouped together for the presence of critical values in one or two indexes but relatively comfortable values on the other measurements. Lastly, the most comfortable soprano roles are Maria, Desdemona, Donna Leonora and Alice, concluding with Nannetta. 
The evolution of female voices in Verdi's opera is also characterized by the gradual decline of contralto voice and a more decisive development of mezzosoprano voice. Mezzosopranos and contraltos were therefore analyzed together as both voice types can perform the roles of the characters included in this category. The roles of Azucena, Fenena, and Preziosilla are characterized by generally high values of $\% \mathrm{Hp}$ balanced with high \%Mt but differed for duration parameters. The \%Lp increases in the scores of Eboli and Amneris together with a decrease in the $\% \mathrm{Mp}$. Markedly low values of \%Mt mark the role of Quickly; moreover, the highest value of \%Lp was found for this character compared to the other of the group increasing the vocal demand required from the performer. A notable $\% \mathrm{Lp}$ was also found for Ulrica. Although a rank based on vocal effort is hard to be established for mezzosoprano and contralto roles because of their heterogeneity, the role of Maddalena is undoubtedly the most vocally comfortable because of its shortness, and the high presence of medium pitched notes.

As for the sopranos, also Verdi's tenor roles are generally characterized by a limited \%Hp in favor of high values of $\% \mathrm{Mp}$ with roles of the early operas being more demanding than those of the late operas. Therefore, the typical register of the tenor voice is not emphasized and was progressively reduced over the years of production. The role of Macduff represents an exception to the above-mentioned trend; indeed, the high pitched notes were the $34.25 \%$ of the score. The high $\% \mathrm{Hp}$ along with the high $\% \mathrm{P}$ make this role highly costly for the singer, except for its shortness. Overall, the role of Arrigo seems to be the most demanding among tenor characters because of the important TPT, the low $\% \mathrm{Mt}$, and the high $\% \mathrm{P}$. Proceeding to less challenging roles based on the estimated vocal effort from the VSP, Ernani, Duca, Don Carlo and Otello can be placed in the second position. Besides an important TPT, the first two characters have significant $\% \mathrm{Hp}$ and $\% \mathrm{P}$ together with low \%Mt, while Don Carlo and Otello exhibit the highest values of \%Lp. Consecutively, the remaining roles can be ranked as follows: Riccardo and Manrico, Radames and Alvaro, Alfredo-Ismaele-Macduff, Fenton and Gabriel and, lastly, Cassio.

Baritones obtained an autonomy from the bass voice type in Verdi's operas, defining their own range and tessitura and becoming the principal male voice type. A gradual transition to a greater predominance of the low register to the detriment of the medium register can be observed from the percentage of low-pitched and medium-pitched notes as well as from the limits of the PO. Compared to tenors, the baritone roles are 
distinguished by a lower $\% \mathrm{P}$ never exceeding the $10 \%$ and higher $\% \mathrm{Mt}$, making these roles generally more comfortable than the previous. Rigoletto, Iago, and Falstaff have the longest TPT and wide PR. The roles of Macbeth, Monforte, and Carlo V exhibit high \%P beside high TPT. The lowest vocal effort is required when performing the role of Amonasro, Paolo, and Melitone mainly due to their brevity.

Lastly, bass roles are associated with minor characters in the operas analyzed. The role of Procida stands out for the long TPT, the role of Zaccaria for the high \%Hp and the role of Padre Guardiano for the high \%Lp. In spite of the markedly reduced duration, the roles of Sparafucile and Inquisitore can be distinguished for the high $\% \mathrm{Hp}$ and $\% \mathrm{P}$. The minimum vocal effort is associated with the role of Banco, in light of the short TPT and high \%Mt.

In the present study, the methodology used to gain data for the construction of the VSP and to calculate the pitch indexes was the same used by the first author (G.M.) in a previous study on Puccini's scores [13]. However, notes counting did not differ from Fussi and colleagues' VSP [8]. Concerning pitch measurements, the authors list five more indexes in addition to those used in the present study: the percentage of high-pitched notes excluded the passaggio notes for male and soprano roles, the percentage of low-pitched notes excluded the passaggio note for mezzosoprano and contralto roles, the rate between the two previous indexes and the $\% \mathrm{P}$, the percentage of extreme register notes obtain by summing the $\% \mathrm{Hp}$ to the $\% \mathrm{Lp}$, the rate between the $\% \mathrm{Mt}$ and \%PO. Although these indexes were not calculated for the 67 Verdi roles, the reader may compute them by the data collected in the study. Analogously, the estimated cycle dose proposed by Titze could be gained by multiply the absolute frequency by the Hertz frequency of each note in a role [9].

Several shortcomings of the VSP can be identified. First of all, as stated in the methods section, the allocation of notes to the low, medium and high register was based on average register's limits values reported in previous works. However, individual differences in the pitch of passaggio notes exist based on anatomy, singing training, technical skills, experience, interpreted character as well as environmental factors related to the performance. Moreover, variations within a voice category (f.i. bass-baritone, French baritone) were not taken into account in the present paper. 
Secondly, the analysis of a role based on the VSP is limited to the information of the score that can be objectively studied. However, the potential suitability of a role to a singer concerning the vocal demand depends also on dynamic indications, particularly the pianissimo and fortissimo which require advanced technical skills to finely balance the subglottic pressure and vocal fold closure. Moreover, it is known that the vowels may influence the phonatory stability in the passaggio region and therefore its difficulty [25]. The size of the orchestra and the acoustics of the auditorium are additional factors influencing vocal demand of a role.

Acknowledging its limits, the VSP provides objective and aggregated data that can be easily and quickly examined by both expert singers and healthcare providers who did not undergo a specific music training. Sharing these data between singers, singing teachers and clinicians may improve the multidisciplinary approach to the care of the singer by creating a common language among different stakeholders. The objective data from the VSP can be used by singers, singing teachers and vocal coaches in repertoire selection but always along with other information such as age, gender, personality, preferences, technical and expressive skills. Potentially, from the comparison between the VSP of a role and the performance VRP of a singer, overlaps and gaps may be suggestive of the feasibility of a role and may highlight potential risk to the vocal health of the singer. Addressing this information during counseling may allow greater customization of the recommendation the clinicians give to the opera singer together with general vocal hygiene advice both in physiological and in pathological situations. When laryngeal abnormalities already occur, the analysis of the previous repertoire may highlight possible causal relationships and may afterward guide the conduction of the voice therapy by the SLT. Nevertheless, the true relationship between performed repertoire and vocal health is still not explored in the literature. The predictive value of the indexes used in the study in appraising the risk of vocal injury must be investigated in future studies, together with other factors as mentioned earlier, to understand better the actual benefit derived from the application of the VSP in both educational and clinical practice. 


\section{References}

1. P.M. Pestana, S. Vaz-Freitas, M.C. Manco, Prevalence of voice disorder in singers: systematic review and meta-analysis, J. Voice 2017 Mar 22. doi: 10.1016/j.jvoice.2017.02.010. [Epub ahead of print]

2. J. Guss, B. Sadoughi, B. Benson, L. Sulica, Dysphonia in performers: toward a clinical definition of laryngology of the performing voice, J. Voice 28 (2014) 349-355.

3. W. Crutchfield, Vocal Burnout At The Opera, New York Times, 1986 September 21.

4. H.C. Schonberg, Domingo, Like Other Great Singers, Becomes Wary About His Voice, New York Times, 1983 September 26.

5. J. Calvet, Etudes phonometriques, in: La Voix, Cours International de Phonologie et Phoniatrie, Libraire Maloine, Paris, 1953, pp. 67-78.

6. F. Klingholz, The Voice Field: A practical guide for measurement and evaluation (in German), Verlag J. Peperny, Munchen, 1990.

7. A. Lamarche, S. Ternström, P. Pabon, The singer's voice range profile: female professional opera soloists, J. Voice 24 (2010) 410-426.

8. S. Thurmer, The tessiturogram, J. Voice 2 (1988) 327-329.

9. I. Titze, Quantifying tessitura in a song, J. Singing 65 (2008) 59-61.

10. F. Fussi, M. Gilardone, N. Paolillo, Il Vocal Score Profile e il rapporto partiturografia/fonetografia, in: F. Fussi (Ed.), La Voce del Cantante. vol.4 (in Italian), Omega, Torino, 2007, pp. 79-118.

11. J. Nix, Measuring Mozart: a pilot study testing the accuracy of objective methods for matching a song to a singer, J. Singing 70 (2014) 561-572.

12. Opera Base, Opera statistics 2015/2016. http://operabase.com/visual.cgi?lang=en\&splash=t (accessed on 01 February 2017).

13. M. Gilardone, F. Fussi, Elementi di fisiologia vocale nel canto, in: M. Gilardone, F. Fussi (Eds.) Le Voci di Puccini, un'indagine sul canto (in Italian), Omega, Torino, 1998, pp. 11-43.

14. J. Budden, The operas of Verdi, Claredon Press, Oxford, 1973.

15. R.W. Young, Terminology of logarithmic frequency units, J. Acoust. Soc. Am. 11 (1939) 134.

16. R. Miller, The Structure of Singing: System and Art in Vocal Technique, Schirmer Books, New York, 1986, pp. 115-149.

17. I. Titze, The Principles of Voice Production, Second Printing, National Center for Voice and Speech, Iowa City, 2000, p. 282.

18. G. Landini, M. Gilardone, Dal Labbro il Canto (in Italian), Omega, Turin, 2001.

19. M. David, The New Voice Pedagogy, 2nd edn, The Scarecrow Press, Lanham, 2008, p. 70.

20. J. Sundberg, J. Titze, R. Scherer, Phonatory control in male singing: a study of the effects of subglottal pressure, fundamental frequency, and mode of phonation on the voice source, J. Voice 7 (1993) 15-29. 
21. J.R. Titze, Principles of voice production, Prentice Hall, NJ, 1994.

22. J.G. Svec, J. Sundberg, S. Hertegard, Three registers in an untrained female singer analyzed by videokymography, strobolaryngoscopy and sound spectrography, J. Acoust. Soc. Am. 123 (2008) 347-353.

23. M. Echternach, F. Burk, M. Köberlein, A. Selamtzis, M. Döllinger, M. Burdumy, B. Richter, C.T. Herbst, Laryngeal evidence for the first and second passaggio in professionally trained sopranos, PLoS One 12 (2017) $\mathrm{e} 0175865$.

24. M. Echternach, F. Burk, M. Burdumy, C.T. Herbst, M. Köberlein, M. Döllinger, B. Richter, The influence of vocal fold mass lesions on the passaggio region of professional singers, Laryngoscope 127 (2017) 13921401 .

25. M. Echternach, F. Burk, M. Köberlein, M. Burdumy, M. Döllinger, B. Richter, The Influence of Vowels on Vocal Fold Dynamics in the Tenor's Passaggio, J. Voice 31 (2017) 424-429.

\author{
Abbreviations' list \\ $\mathrm{Hp} / \mathrm{Lp}=$ high-pitched and low-pitched notes rate \\ $\mathrm{PO}=$ prevalent octave \\ $\mathrm{PR}=$ pitch range \\ $\mathrm{TPT}=$ totale phonation time \\ $\% \mathrm{Mt}=$ percentage of notes at a moderate range tessitura \\ $\% \mathrm{Hp}=$ percentage of high-pitched notes \\ $\% \mathrm{Mp}=$ percentage of medium-pitched notes \\ $\% \mathrm{Lp}=$ percentage of low-pitched notes \\ $\% \mathrm{P}=$ percentage of notes in the passaggio \\ $\% \mathrm{PO}=$ percentage of notes belonging to the $\mathrm{PO}$
}


Vitae

Nicole Pizzorni Born in Milan (Italy) in 1990. Speech and Language Therapist degree in 2012, Rehabilitation Sciences degree in 2014 (University of Milan). Working with people with voice, communication and swallowing disorders since 2014 at the Department of Neurorehabilitation Sciences of Casa di Cura del Policlinico. Currently a Ph.D. student in Nutritional Sciences (University of Milan).

Antonio Schindler Born in Turin (Italy) in 1972. Medical degree in 1997 (University of Turin), specialization in Phoniatry in 2001, specialization Otorhinolaryngology in 2005 (University of Milan). Researcher of Otorhinolaryngology (University of Milan) from 2006 to 2015, Associate professor of Audiology (University of Milan) since 2015.

Matteo Sozzi Born in Lecco (Italy) in 1976. Psychology Master Degree in 2001 (University of Padua), Ph.D. in Cognitive Sciences in 2006 (University of Padua). During the last 16 years, he acquired experience in clinical neuropsychology working both in clinical setting and research focusing also on case observations of selective amusias in after brain lesions. Since 2008 he is the chief of Neuropsychology Service in the Department of Neuro Rehabilitation Sciences of Casa di Cura del Policlinico.

Massimo Corbo Born in Como (Italy) in 1957. Medical degree, specialization in Neurology (University of Milan). Completed his training as a researcher at Columbia University in New York. He has worked in several internationally recognized Clinical Centers, including the San Raffaele Hospital, the Italian Auxologic Institute and the Niguarda Ca 'Granda Hospital in Milan, where he has deepened his knowledge and experience in the field of Neurodegenerative and Neuromuscular Diseases. He is currently the Scientific Director of the Casa Cura Policlinico, Department of Neurorehabilitation Sciences and Hospital Center for Intensive Neurorehabilitation in Milan.

Marco Gilardone Born in Tortona (Italy) in 1963. Medical degree in 1990, specialization in Phoniatry in 1995 (Universit of Milan); specialization in Audiology in 2000 (University of Turin). He has worked as a Phoniatrician at IRCCS Fondazione S. Maugeri in Pavia and European Institute of Oncology (IEO) in Milan. Currently, he is the Director of Phoniatry, Audiology and Speech Pathology Unit at Department of Neurorehabilitation Sciences, Casa di Cura del Policlinico (CCP) in Milan. 
Table 1: Register distribution in different voice type

\begin{tabular}{|c|c|c|c|c|c|c|c|c|c|c|c|c|}
\hline & \multicolumn{2}{|c|}{ Soprano } & \multicolumn{2}{|c|}{ Tenor } & \multicolumn{2}{|c|}{ Mezzo-soprano } & \multicolumn{2}{|c|}{ Baritone } & \multicolumn{2}{|c|}{ Contralto } & \multicolumn{2}{|c|}{ Bass } \\
\hline & $\begin{array}{c}\text { Upper } \\
\text { limit }\end{array}$ & $\begin{array}{c}\text { Lower } \\
\text { limit }\end{array}$ & $\begin{array}{c}\text { Upper } \\
\text { limit }\end{array}$ & $\begin{array}{c}\text { Lower } \\
\text { limit }\end{array}$ & $\begin{array}{c}\text { Upper } \\
\text { limit }\end{array}$ & $\begin{array}{c}\text { Lower } \\
\text { limit }\end{array}$ & $\begin{array}{c}\text { Upper } \\
\text { limit }\end{array}$ & $\begin{array}{c}\text { Lower } \\
\text { limit }\end{array}$ & $\begin{array}{c}\text { Upper } \\
\text { limit }\end{array}$ & $\begin{array}{c}\text { Lower } \\
\text { limit }\end{array}$ & $\begin{array}{c}\text { Upper } \\
\text { limit }\end{array}$ & $\begin{array}{c}\text { Lower } \\
\text { limit }\end{array}$ \\
\hline Upper register & Hpn & F4-5 & $\mathrm{Hpn}$ & $F \# 4-5$ & Hpn & $E b 4-5$ & Hpn & E4-5 & Hpn & C\#4-5 & Hpn & $D 4-5$ \\
\hline Medium register & E4-5 & A3-4 & E4-5 & A3-4 & D4-5 & G3-4 & A4-5 & G3-4 & C4-5 & F3-4 & $\mathrm{C} 4-5$ & F3-4 \\
\hline Lower register & G3-4 & Lpn & $G \# 3-4$ & Lpn & $F 3-4$ & Lpn & $F \# 3-4$ & Lpn & $E b 3-4$ & Lpn & $E 3-4$ & Lpn \\
\hline
\end{tabular}

NOTE: Primo and secondo passaggio are in italics

Abbreviations: $\mathrm{Hpn}=$ Highest-pitched note; $\mathrm{Lpn}=$ Lowest-pitched note 
Table 2: Average metronome markings and quarter note's duration for each tempo or mood indication

\begin{tabular}{|l|c|c|}
\hline & $\begin{array}{c}\text { Metronome marking for the } \\
\text { quarter note }\end{array}$ & Quarter note's duration (s) \\
\hline Largo & 50 & 1.20 \\
\hline Larghetto & 63 & 0.95 \\
\hline Adagio & 71 & 0.84 \\
\hline Adagietto & 74 & 0.81 \\
\hline Andante & 90 & 0.66 \\
\hline Andantino & 97 & 0.61 \\
\hline Moderato & 112 & 0.53 \\
\hline Allegro & 144 & 0.41 \\
\hline Allegretto & 156 & 0.38 \\
\hline Presto & 184 & 0.32 \\
\hline Prestissimo & 204 & 0.29 \\
\hline Recitativo secco & 108 & 0.55 \\
\hline
\end{tabular}


Table 3: Pitch and duration measurements for soprano roles

\begin{tabular}{|c|c|c|c|c|c|c|c|c|c|c|c|}
\hline Role & Opera & PR & \%Hр & \%Мp & \%Lp & Hp/Lp & $\% \mathrm{P}$ & $\mathbf{P O}$ & $\% \mathrm{PO}$ & \%Mt & TPT \\
\hline Abigaille & Nabucodonosor & B3-C6 & 20.85 & 56.75 & 22.4 & 1.07 & 11.27 & G4-5 & 81.16 & 65.33 & 20'32', \\
\hline Elvira & Ernani & G\#3-C6 & 25.96 & 57.38 & 16.66 & 1.55 & 13.09 & G4-5 & 83.27 & 63.86 & $24^{\prime} 12^{\prime \prime}$ \\
\hline Lady Macbeth & Macbeth & $\mathrm{Bb3}-\mathrm{C} \# 6$ & 20.68 & 52.71 & 26.61 & 0.77 & 11.13 & F4-5 & 81.39 & 74.41 & $25^{\prime} 34^{\prime \prime}$ \\
\hline Gilda & Rigoletto & $\mathrm{Bb3}-\mathrm{C} \# 6$ & 21.62 & 63.87 & 14.05 & 1.49 & 10.99 & $\mathrm{G} \# 4-5$ & 86.1 & 68.31 & $21^{\prime} 46^{\prime \prime}$ \\
\hline Leonora & Il trovatore & $\mathrm{G} \# 3-\mathrm{C} \# 6$ & 17.71 & 57.31 & 24.98 & 0.7 & 10.09 & G4-5 & 84.08 & 70.08 & $28^{\prime} 53^{\prime \prime}$ \\
\hline Violetta & La traviata & B3-C\#6 & 16.31 & 65.83 & 17.86 & 0.91 & 8.55 & G4-5 & 89.01 & 76.89 & $38^{\prime} 51^{\prime \prime}$ \\
\hline Elena & $\begin{array}{l}\text { Les vêpres } \\
\text { siciliennes }\end{array}$ & $\mathrm{F} \# 3-\mathrm{C} \# 6$ & 16.35 & 55.33 & 28.32 & 0.57 & 8.02 & F4-5 & 77.83 & 73.07 & $38^{\prime} 11^{\prime \prime}$ \\
\hline Maria & Simon Boccanegra & $\mathrm{Bb} 3-\mathrm{C} 6$ & 16.14 & 61.62 & 22.24 & 0.72 & 9.17 & F\#4-5 & 84.71 & 75.54 & $16^{\prime} 56^{\prime \prime}$ \\
\hline Amelia & $\begin{array}{c}\text { Un ballo in } \\
\text { maschera }\end{array}$ & A3-C6 & 18.17 & 55.24 & 26.59 & 0.68 & 9.1 & F4-5 & 81 & 74.4 & $22^{\prime} 07^{\prime \prime}$ \\
\hline Oscar & $\begin{array}{l}\text { Un ballo in } \\
\text { maschera }\end{array}$ & $\mathrm{C} 4-\mathrm{C} 6$ & 22.29 & 64.63 & 13.09 & 1.7 & 12.37 & G4-5 & 88.44 & 71.39 & $16^{\prime} 21^{\prime \prime}$ \\
\hline Donna Leonora & La forza del destino & Bb3-B5 & 11.26 & 61.62 & 27.12 & 0.41 & 6.59 & E4-5 & 84.18 & 84.18 & $21^{\prime} 10^{\prime \prime}$ \\
\hline Elisabetta & Don Carlos & $\mathrm{Bb3}-\mathrm{B} 5$ & 13.02 & 57.24 & 29.74 & 0.43 & 7.98 & F4-5 & 85.02 & 80.14 & $24^{\prime} 50^{\prime \prime}$ \\
\hline Aida & Aida & B3-C6 & 15.61 & 57.18 & 27.21 & 0.57 & 7.82 & F4-5 & 79.63 & 75.24 & $21^{\prime} 20^{\prime \prime}$ \\
\hline Desdemona & Otello & Bb3-B5 & 11.81 & 55.16 & 33.03 & 0.35 & 7.67 & F4-5 & 80.32 & 75.2 & $16^{\prime} 12^{\prime \prime}$ \\
\hline Alice & Falstaff & Bb3-C6 & 9.05 & 63.14 & 27.81 & 0.32 & 5.64 & F4-5 & 68.4 & 62.07 & $20^{\prime} 45^{\prime \prime}$ \\
\hline Nannetta & Falstaff & Bb3-C6 & 9.05 & 67.91 & 23.04 & 0.39 & 4.41 & $\mathrm{~F} \# 4-5$ & 88.88 & 84.47 & 12'34' \\
\hline
\end{tabular}


Table 4: Pitch and duration measurements for mezzosoprano and contralto roles

\begin{tabular}{|c|c|c|c|c|c|c|c|c|c|c|c|}
\hline Role & Opera & PR & $\% \mathrm{Hp}$ & \%Мp & \%Lp & Hp/Lp & $\% \mathbf{P}$ & $\mathbf{P O}$ & $\% \mathrm{PO}$ & \%Mt & TPT \\
\hline Fenena & Nabucodonosor & B3-A5 & 16.18 & 64.31 & 19.61 & 0.82 & 12.21 & E4-5 & 89.87 & 75.15 & 7'53'’ \\
\hline Maddalena & Rigoletto & B3-F\#5 & 1.05 & 73.52 & 25.43 & 0.04 & 10.54 & D4-5 & 94.72 & 73.51 & $63^{\prime} 43^{\prime}$ \\
\hline Azucena & Il trovatore & A3-C6 & 14.26 & 66.69 & 19.05 & 0.74 & 7.86 & E4-5 & 87.94 & 75.28 & $18^{\prime} 23^{\prime \prime}$ \\
\hline Ulrica & $\begin{array}{l}\text { Un ballo in } \\
\text { maschera }\end{array}$ & G3-G\#5 & 9.05 & 53.66 & 37.29 & 0.24 & 16.83 & E4-5 & 83.8 & 59.63 & 9’14', \\
\hline Preziosilla & $\begin{array}{c}\text { La forza del } \\
\text { destino }\end{array}$ & A3-C6 & 19.58 & 60.24 & 20.18 & 0.96 & 9.02 & E4-5 & 87.56 & 72.98 & $12^{\prime} 50^{\prime \prime}$ \\
\hline Eboli & Don Carlos & $\mathrm{Bb} 3-\mathrm{B} 5$ & 14.05 & 54.03 & 31.92 & 0.44 & 16.59 & E4-5 & 85.6 & 61.72 & $18^{\prime} 34^{\prime \prime}$ \\
\hline Amneris & Aida & $\mathrm{Bb} 3-\mathrm{B} 5$ & 13.36 & 54.85 & 31.79 & 0.42 & 12.69 & Eb4-5 & 82.17 & 58.59 & $21 ' 24 \prime \prime$ \\
\hline Quickly & Falstaff & G3-G5 & 3.71 & 49.08 & 47.21 & 0.07 & 12.13 & C4-5 & 85.74 & 43.4 & $15^{\prime} 12^{\prime \prime}$ \\
\hline
\end{tabular}


Table 5: Pitch and duration measurements for tenor roles

\begin{tabular}{|c|c|c|c|c|c|c|c|c|c|c|c|}
\hline Role & Opera & PR & \%Нp & \%Мр & \%Lp & Hp/Lp & $\% \mathrm{P}$ & $\mathbf{P O}$ & $\%$ PO & \%Mt & TPT \\
\hline Ismaele & Nabucodonosor & $\mathrm{B} 2-\mathrm{Bb} 4$ & 28 & 62.98 & 9.04 & 3.1 & 19.29 & A3-4 & 90.88 & 62.97 & 9'54', \\
\hline Ernani & Ernani & $\mathrm{Bb} 2-\mathrm{Bb} 4$ & 22.72 & 66.24 & 10.04 & 2.36 & 13.68 & G3-4 & 92.24 & 71.57 & $25^{\prime} 51^{\prime \prime}$ \\
\hline Macduff & Macbeth & $\mathrm{B} 2-\mathrm{Bb} 4$ & 34.25 & 51.73 & 14.02 & 2.44 & 23.04 & $\mathrm{G} \# 3-4$ & 90.16 & 57.29 & $10^{\prime} 02^{\prime \prime}$ \\
\hline Duca di Mantova & Rigoletto & C3-B4 & 24.22 & 64.74 & 11.04 & 2.19 & 15.18 & G\#3-4 & 92.82 & 69.94 & $22^{\prime} 23^{\prime \prime}$ \\
\hline Manrico & Il trovatore & $\mathrm{C} \# 3-\mathrm{Bb} 4$ & 23.15 & 68.4 & 8.5 & 2.71 & 13.65 & G3-4 & 95.49 & 75.81 & $22^{\prime} 55^{\prime \prime}$ \\
\hline Alfredo & La traviata & Eb3-Bb4 & 19.92 & 69.85 & 10.23 & 1.94 & 11.69 & G3-4 & 93.75 & 77.27 & $23^{\prime} 12^{\prime \prime}$ \\
\hline Arrigo & $\begin{array}{l}\text { Les vêpres } \\
\text { siciliennes }\end{array}$ & C3-D5 & 23.1 & 65.37 & 11.53 & 2 & 14.26 & G\#3-4 & 90.94 & 70.21 & $38^{\prime} 34^{\prime \prime}$ \\
\hline Gabriele & Simon Boccanegra & $\mathrm{C} 3-\mathrm{Bb} 4$ & 20.02 & 67.1 & 12.88 & 1.55 & 11.7 & $\mathrm{G} \# 3-4$ & 89.71 & 71.62 & $14^{\prime} 32^{\prime \prime}$ \\
\hline Riccardo & $\begin{array}{c}\text { Un ballo in } \\
\text { maschera }\end{array}$ & $\mathrm{Bb} 2-\mathrm{Bb} 4$ & 18.3 & 64.9 & 16.8 & 1.08 & 11.11 & G3-4 & 89.19 & 74.4 & $27^{\prime} 15^{\prime}$ \\
\hline Don Alvaro & La forza del destino & $\mathrm{Bb} 2-\mathrm{Bb} 4$ & 17.98 & 65.42 & 16.6 & 1.08 & 10.24 & G3-4 & 88.77 & 74.75 & $20^{\prime} 43^{\prime \prime}$ \\
\hline Don Carlo & Don Carlos & C3-B4 & 15.86 & 65.9 & 18.24 & 0.86 & 9.04 & G3-4 & 90.69 & 78.53 & $29^{\prime} 45^{\prime \prime}$ \\
\hline Radames & Aida & $\mathrm{Bb} 2-\mathrm{Bb} 4$ & 19.93 & 65.52 & 14.55 & 1.37 & 11.3 & G3-4 & 87.35 & 71.79 & $19^{\prime} 51^{\prime \prime}$ \\
\hline Cassio & Otello & C3-B4 & 19.08 & 66.94 & 13.98 & 1.36 & 11.84 & G3-4 & 88.38 & 74.17 & 6'41', \\
\hline Otello & Otello & $\mathrm{B} 2-\mathrm{C} 5$ & 16.62 & 65.07 & 18.31 & 0.9 & 10.54 & G3-4 & 89.97 & 76.66 & $23^{\prime} 58^{\prime \prime}$ \\
\hline Fenton & Falstaff & C\#3-B4 & 17.54 & 67.09 & 15.37 & 1.13 & 9.66 & G3-4 & 91.05 & 78.08 & 8'54', \\
\hline
\end{tabular}


Table 6: Pitch and duration measurements for baritone roles

\begin{tabular}{|c|c|c|c|c|c|c|c|c|c|c|c|}
\hline Role & Opera & $\mathbf{P R}$ & \%Hр & \%Мр & $\%$ Lp & Hp/Lp & $\% \mathrm{P}$ & $\mathbf{P O}$ & $\%$ PO & $\% \mathbf{M t}$ & TPT \\
\hline Nabucodonosor & Nabucodonosor & B2-G4 & 8.17 & 81.27 & 10.56 & 0.77 & 6.86 & F3-4 & 96.19 & 88.09 & $20 ' 42^{\prime \prime}$ \\
\hline Carlo $V$ & Ernani & A2-G4 & 11.39 & 79.09 & 9.52 & 1.19 & 8.79 & F3-4 & 95.26 & 86.5 & $21^{\prime} 12^{\prime \prime}$ \\
\hline Macbeth & Macbeth & B2-G4 & 8.39 & 77.09 & 13.98 & 0.63 & 7.21 & E3-4 & 94.57 & 87.35 & $22^{\prime} 57^{\prime \prime}$ \\
\hline Rigoletto & Rigoletto & Bb2-G4 & 8.61 & 71.07 & 20.32 & 0.42 & 6.63 & Eb3-4 & 93.14 & 88.1 & $27^{\prime} 18^{\prime \prime}$ \\
\hline Conte di Luna & Il trovatore & G\#2-G4 & 9.11 & 72.25 & 18.64 & 0.48 & 6.03 & Eb3-4 & 91.34 & 87.47 & $21^{\prime} 16^{\prime \prime}$ \\
\hline Germont & La traviata & $\mathrm{Bb} 2-\mathrm{F} \# 4$ & 9.04 & 73.84 & 17.14 & 0.52 & 6.76 & Eb3-4 & 94.32 & 88.1 & $15^{\prime} 31^{\prime \prime}$ \\
\hline Monforte & $\begin{array}{l}\text { Les vêpres } \\
\text { siciliennes }\end{array}$ & G\#2-G4 & 8.98 & 66.81 & 24.21 & 0.37 & 7.32 & Eb3-4 & 91.55 & 87.33 & $23^{\prime} 12^{\prime \prime}$ \\
\hline Simon Boccanegra & Simon Boccanegra & $\mathrm{B} 2-\mathrm{F} \# 4$ & 6.65 & 77.97 & 15.38 & 0.43 & 5.42 & E3-4 & 95.13 & 89.71 & $20 ' 52^{\prime \prime}$ \\
\hline Paolo & Simon Boccanegra & B2-F4 & 2.51 & 67.86 & 29.63 & 0.08 & 2.14 & Eb3-4 & 92.92 & 90.95 & 8'38', \\
\hline Renato & $\begin{array}{l}\text { Un ballo in } \\
\text { maschera }\end{array}$ & A2-G4 & 7.74 & 67.07 & 25.19 & 0.3 & 5.49 & Eb3-4 & 90.96 & 87.7 & $21^{\prime} 50^{\prime \prime}$ \\
\hline Don Carlo & La forza del destino & $\mathrm{Bb} 2-\mathrm{F} \# 4$ & 10.61 & 67.48 & 21.91 & 0.48 & 9.41 & E3-4 & 94.07 & 84.66 & 14'39', \\
\hline Melitone & La forza del destino & G2-G4 & 7.92 & 68.81 & 23.27 & 0.33 & 6.48 & E3-4 & 91 & 89.52 & 13'22'” \\
\hline Rodrigo & Don Carlos & G\#2-G4 & 6.44 & 70.48 & 23.08 & 0.27 & 4.79 & Eb3-4 & 93.33 & 90.58 & 21'14', \\
\hline Amonasro & Aida & $\mathrm{A} 2-\mathrm{F} \# 4$ & 8.75 & 69.46 & 21.78 & 0.41 & 6.69 & Eb3-4 & 90.57 & 85.67 & 7'56' \\
\hline Iago & Otello & F\#2-A4 & 4.71 & 65.65 & 29.64 & 0.15 & 3.42 & D3-4 & 90.21 & 90.21 & 27'02', \\
\hline Falstaff & Falstaff & G2-G4 & 5.41 & 62.67 & 31.92 & 0.16 & 4.21 & D3-4 & 90.38 & 90.38 & 29'13', \\
\hline Ford & Falstaff & F2-G4 & 7.31 & 57.58 & 35.11 & 0.2 & 6.1 & D3-4 & 86.92 & 86.92 & 19'23', \\
\hline
\end{tabular}


Table 7: Pitch and duration measurements for bass roles

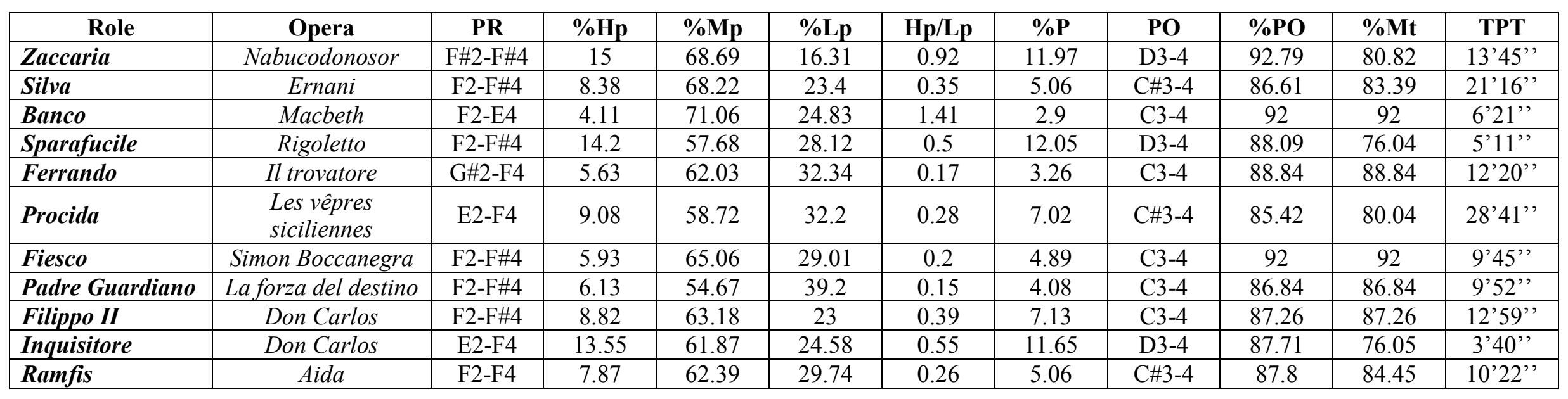


Figure 1: Pitch distribution in three tenor roles (absolute frequency) 
Figure 2: Pitch distribution in three tenor roles (relative frequency) 
Fig. Vitae

Nicole Pizzorni

Antonio Schindler

Matteo Sozzi

Massimo Corbo

Marco Gilardone 